\title{
Experimental Analysis of Hydrogen Energy share in a compressed ignition engine under dual fuel mode with Karanja B20 at different Injection Operating Pressures
}

\author{
Kursam Krishna $^{\# 1}$, Bellam Sudheer Prem Kumar ${ }^{* 2}$ \\ \# Research Scholar, Mechanical Engineering, JNT University, \\ Kukatpally, Hyderabad, Telangana, India-500085 \\ ${ }^{1}$ krishna.kursam@gmail.com \\ ${ }^{* 2}$ Professor, Department of Mechanical Engineering, JNT University, \\ Kukatpally, Hyderabad, Telangana, India-500085 \\ 2bsudheerpk@yahoo.co.in
}

Abstract - The present experiment is to improvement of hydrogen energy share in $3.5 \mathrm{~kW}$ single cylinder direct injection diesel engine under dual fuel mode. The experimental test is conducted at the injection operating pressure (IOP) varying from 200 to 240 bar using pure diesel, B20, and B20 with various less concentration flow rate of hydrogen at $100 \%$ load with $1500 \mathrm{rpm}$ constant. The acquisition data of the test fuels is compared with 200 bar pressure of diesel baseline. The energy share of hydrogen for performance parameters like Brake thermal efficiency (BTE) is high with maximum IOP and also the specific fuel consumption (SFC) reducing with increasing with maximum IOP. The combustion parameters of Net Heat Release Rate (NHRR) and Cylinder Peak pressure also increases with increasing IOP. The emission parameters of $\mathrm{HC}, \mathrm{CO}$, and CO2 reduces with share of hydrogen at high IOP meanwhile the NOx emissions increases with increasing hydrogen and IOP.

Keyword - Dual Fuel Engine, Karanja Oil, Hydrogen, Efficiency, Emissions

\section{INTRODUCTION}

Nowadays fossil fuels are widely used in IC engine combustion applications, which cause dangerous effects to the environment and world geopolitical climate. Diesel engines have been under the process of development in the last few decades so as to meet legislations related to emission control [1]. Many researchers around the world are interested in the field of developing alternate fuels and to alleviate emissions by peripheral means, like use of catalytic convertors and necessary engine modifications. However, some of them have also recommended the use of additives like browns gas, blending vegetable oils with petrol etc to deduct the emissions [2]. The use of vegetable oils in original conventional diesel engines result in decreased thermal efficiency and increased smoke levels. These problems are further compounded owing to higher viscosity, less volatility and reactivity of the unsaturated hydrocarbon (UHC) chains in vegetable oil fuels. Amongst the aforementioned factors, higher viscosity of vegetable oils poses a challenge as it results in high carbon deposits and ring sticking [3,4]. A variety of vegetable oils such as Karanja oil, rapeseed oil, rice bran oil, cottonseed oil, Jatropha oil etc. has been employed as fuels in diesel engines [5]. Along with these, Karanja oil exhibits extremely high-quality properties. It is a non-edible oil and It is a non-edible oil and possesses higher calorific value and higher cetane number when compared to several other fuels. The Karanja plant can mature roughly anywhere including gravely, sandy and saline soils. It thrives well even under drought-like conditions $[6,7]$.

Dual fuel operation mode in diesel engines has the potential to improve performance and reduce emissions [8]. On the flip side, dual fuel process in general pose problems of less efficiency when the concentration of the introduced fuel is less than a least value. This is because a lean mixture of the induced fuel with air does not burn well. Use of fuels with extensive flammability limits and higher burning velocity can decrease these effects. Since vegetable oils typically generate high smoke emissions from diesel engines, dual fuel operation can be adopted as a technique to better their performance. A small quantity of hydrogen can be introduced with air while using vegetable oil as the pilot fuel. Some of the significant properties of pure diesel, Karanja oil and hydrogen are shown in Table I. Due to the absence of carbon, exploit of hydrogen in dual fuel engines will often reduce hydrocarbon and carbon monoxide emissions $[9,10]$. 
In this present work, a single cylinder direct injection diesel engine is modified to work in the dual fuel mode with hydrogen as an introduced fuel. Karanja oil methyl ester (KOME) blend (B20) is used as the injected fuel and most of the engine's energy is derived from it. It is injected by the conventional fuel injection system. Experiments were conducted at a constant speed of $1500 \mathrm{rpm}$, full load conditions and the quantity of hydrogen and Injection Operating pressure were varied. Comparison has been made with results obtained while using base line diesel as the pilot fuel instead of the KOME blend.

\section{EXPERIMENTAL SETUP AND TEST PROCEDURE}

A Single cylinder water cooled DI diesel engine developing $3.5 \mathrm{~kW}$ at $1500 \mathrm{rpm}$ with the fuel of pure diesel. Specifications of the engine details are shown in Table II. A schematic view of experimental set up illustrated in Fig 1.With the help of high-speed digital data acquisition system to traced the output signal of pressure. The piezoelectric transducer and crankshaft position optical encoder were employed for the measurement of cylinder pressure as a function of crank angle. The exhaust emissions of Engine were quantified by advanced MN-05 multi-gas analyzer (5 gas version).

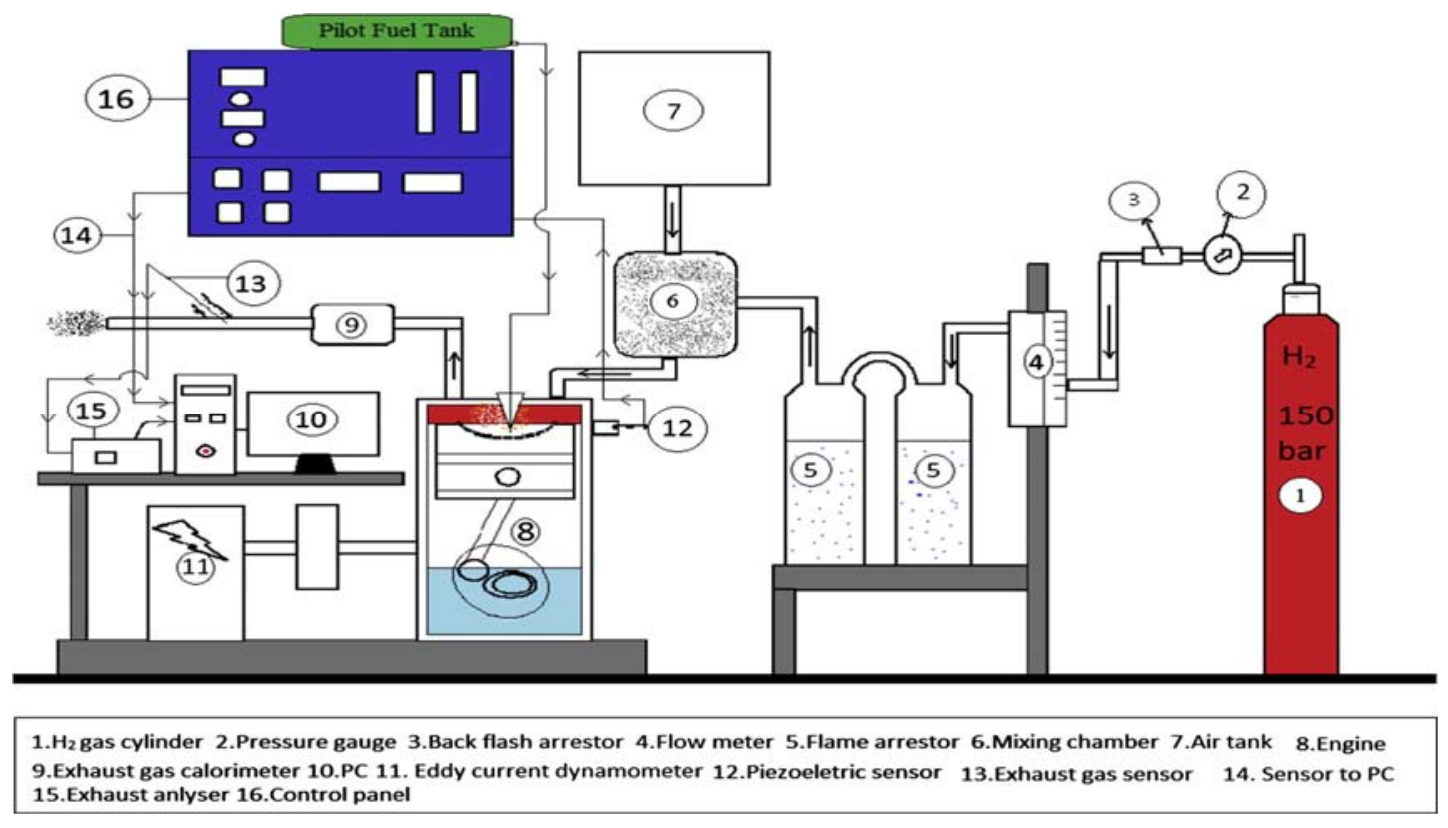

Figure 1 Scamatic diagram of Test Engine

The combustion study was carried on the averaged value of 100 cycles after the engine attained steady state condition. For the duration of the first stage of operation the engine was in progress of fuel on pure diesel to produce baseline data. In the second stage of operation, the engine was made to use on B20 fuel after arriving at stable conditions the outcomes are contrasted to baseline data. In the third stage of process engine running on B20 fuel and inducted air is augmented with a small concentration of hydrogen (5, 10 and $15 \mathrm{lpm})$, the results were achieved at full loading conditions for three different injection opening pressures of 200, 220and 240 bar.

TABLE I: Test Fuel Properties

\begin{tabular}{|l|l|l|l|l|}
\hline \multicolumn{1}{|c|}{ Properties } & Diesel & Hydrogen & B20 & Karanja \\
\hline Density $\left(\mathrm{Kg} / \mathrm{m}^{3}\right)$ & 850 & 0.08 & 831 & 885 \\
\hline Calorific Value $(\mathrm{kj} / \mathrm{Kg})$ & 44500 & 119930 & 42770 & 40750 \\
\hline Viscosity $(\mathrm{gm} / \mathrm{cc})$ & 2.76 & $\cdots$ & 3.88 & 5.12 \\
\hline Flash Point $\left({ }^{\circ} \mathrm{C}\right)$ & 76 & $\cdots$ & 81 & 161 \\
\hline Pour Point $\left({ }^{\circ} \mathrm{C}\right)$ & 3.1 & $\cdots$ & 3.1 & 5.1 \\
\hline Cetane value & 47 & $\cdots$ & 53 & 56.65 \\
\hline Acid Value $(\mathrm{mg} \mathrm{KOH} / \mathrm{g})$ & $\cdots$ & $\cdots$ & $\cdots$ & 1.13 \\
\hline Sp.gravity & 0.835 & 0.091 & 0.844 & 0.937 \\
\hline
\end{tabular}




\section{A. Analysis of Heat Release}

The equation of first law analysis has shown below equation 1, which is used to calculate the heat releases rate by the average pressure versus crank angle variation on 100 cycles.

$$
\text { Qapp }=\gamma / \gamma-1[P d v]+1 / \gamma-1[V d p]+q w
$$

Where $\mathrm{Q}_{\text {app }}$ is heat release rate, $\gamma$ is the ratio of specific heats, $\mathrm{v}$ the instantaneous volume of the cylinder, $\mathrm{P}$ is the cylinder pressure and $\mathrm{q}_{\mathrm{w}}$ in the Hohenberg equation for wall heat transfer [11].

TABLE II: Engine Specifications

\begin{tabular}{|l|l|}
\hline \multicolumn{1}{|c|}{ Make } & \multicolumn{1}{c|}{ Kirloskar AV-1 } \\
\hline Rated power & $3.7 \mathrm{~kW}, 1500 \mathrm{rpm}$ \\
\hline Bore and stroke & $80 \mathrm{~mm}$ x $110 \mathrm{~mm}$ \\
\hline Compression ratio & $16.5: 1$ \\
\hline Cylinder capacity & $553 \mathrm{cc}$ \\
\hline Dynamometer & Eddy current dynamometer \\
\hline Orifice diameter & $20 \mathrm{~mm}$ \\
\hline Fuel & Diesel and hydrogen \\
\hline Calorimeter & Exhaust gas calorimeter \\
\hline Cooling & Water cooled engine \\
\hline Starting & Hand cranking and auto start \\
\hline
\end{tabular}

III.RESULTS AND DISCUSSION

In this experimentation effects of 200, 220, and 240 bar injection operating pressure (IOP) analyzed with B20 and B20 with flow rate of 5,10, and 15 liters per minute hydrogen at constant speed of dual fuel mode engine on performance, combustion, and emissions are evaluated at $100 \%$ load.

\section{A. Energy Share}

Energy share of Dual fuel injection approach working in this experiment for breakthrough the improved premixed lean combustion. The energy allocation of a fuel generally attains on fuel utilization, calorific value of fuel, and speed of combustion. From the fig.2 shows the difference of B20 energy share with hydrogen flow rate i.e. 5, 10, and $15 \mathrm{lpm}$ at different injection operating pressure. In this investigation acknowledged that the energy release rate of B20 was more from 200 to 240 bar of IOP enumerated at full load in all operating conditions. At the same time from figure 3 shows hydrogen flow rates decreases with increasing pressure. The high pressure fuel injection causes better mixing of pilot fuel and supplement fuel which makes complete combustion of B20 mixture. The energy share percentage of B20 as defined the ratio of energy of pilot injection fuel to sum of pilot injection and supplement fuel in equation (1), and the equation (2) used to calculate the percentage of hydrogen share.

Energy Share of B20=Mass of B20 x Lower heating value of B20

$$
\begin{gathered}
\% \text { B20 Energy share }=\frac{\text { Energy of } B 20 X 100}{(\text { Energy of B20 }+ \text { Energy of Hydrogen })} \\
\% \text { Hydrogen Energy share }=\frac{\text { Energy of Hydrogen } X 100}{(\text { Energy of B20 }+ \text { Energy of Hydrogen })}
\end{gathered}
$$

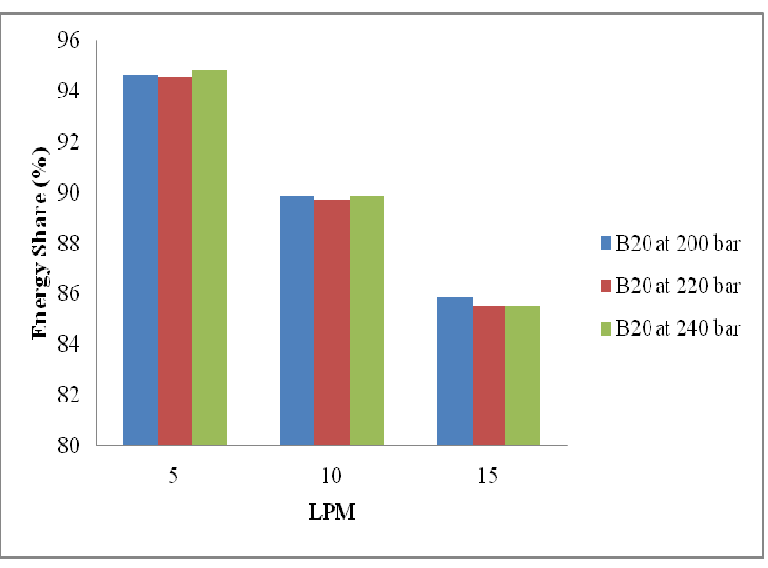

Figure 2 B20 Energy Share vs.H2 Flow rate

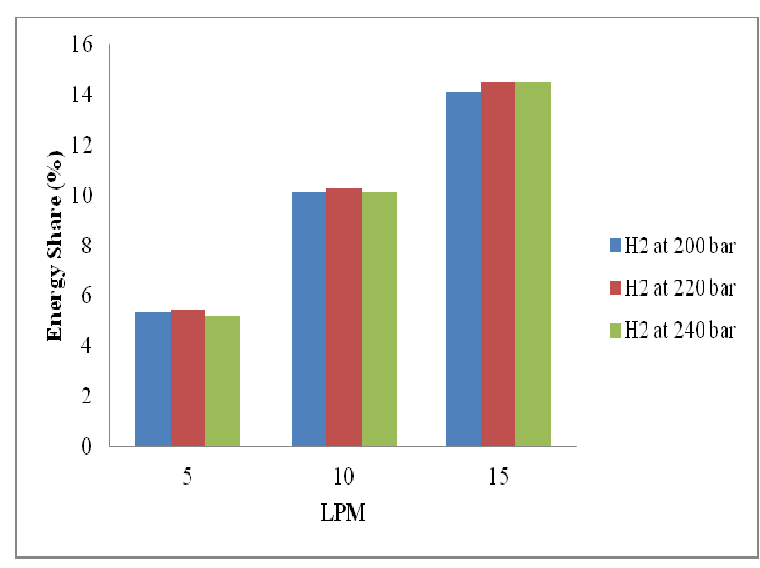

Figure 3 H2 Energy Share vs. H2 Flow Rate 


\section{B. Performance Parameters}

The brake thermal efficiency (BTE) of various fuels is demonstrated below figure 4 as a function of injection operating pressure. The brake thermal efficiency at 200 bar for test fuels of pure diesel, B20, B20+5lpm, B20+10lpm, and B20+15lpm are 21.61, 23.06, 23.16, 24.23, and 26.04\%, while for 240 bar are 22.90, 23.58, $24.99,25.59$, and $27.90 \%$. The brake thermal efficiencies of diesel, B20 and B20 with hydrogen at 5, 10, and $15 \mathrm{lpm}$ of flow rates with diesel base line pressure of 200 bar were seen increased with increase IOP at $100 \%$ load. This is caused by enhanced combustion rate. The propagation of flame through the hydrogen-air mixture leads to rapid heat releases rates and improves the brake thermal efficiency. Efficiencies improved since hydrogen has a very small gap-quenching distance thus allowing complete fuel combustion [12].

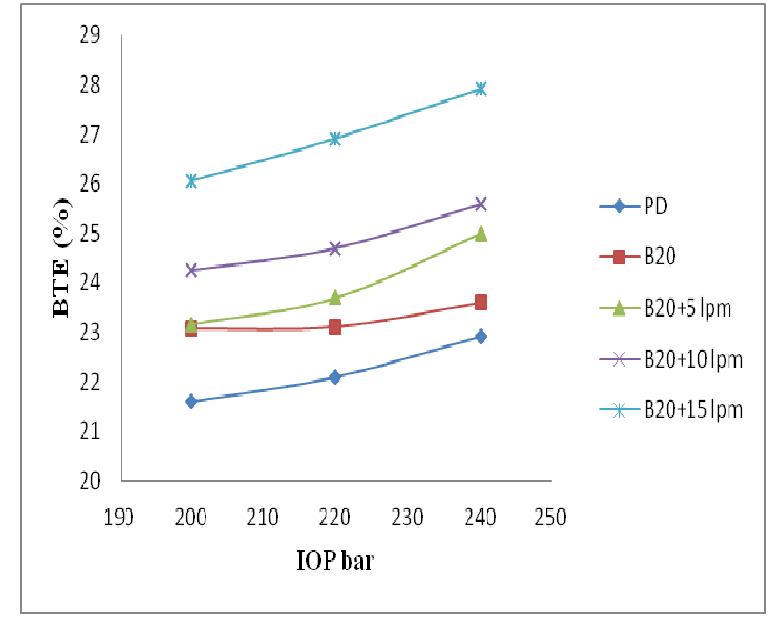

Figure 4 Comparison of BTE vs. IOP

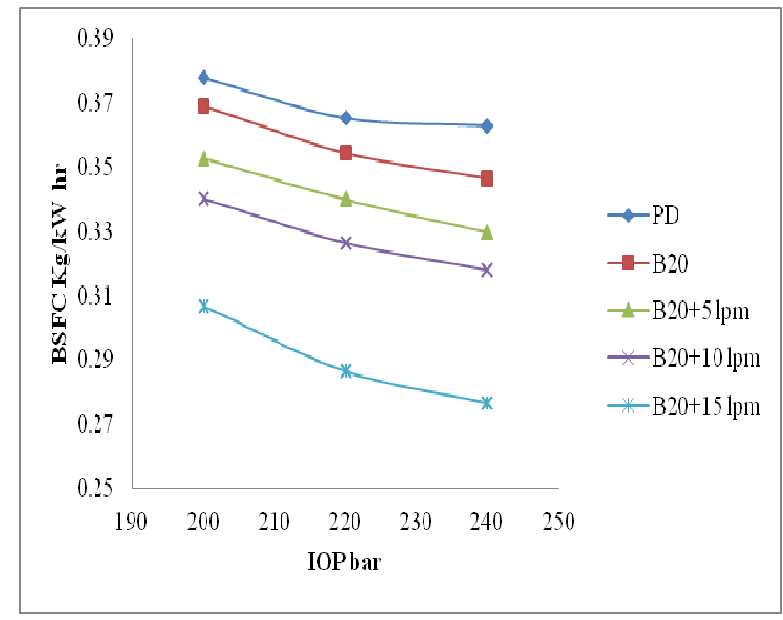

Figure 5 Comparison of BSFC vs. IOP

From figure 5 demonstrates the variation in brake specific fuel consumption (BSFC) with IOP for different test fuels indicates declined with increase in IOP. The brake specific fuel consumption at 200 bar for test fuels of pure diesel, B20, B20+5lpm, B20+10lpm, and B20+15lpm are 0.37, 0.36, 0.35, 0.33 and $0.30 \mathrm{Kg} / \mathrm{kW}-\mathrm{hr}$, while for 240 bar were $0.36,0.34,0.32,0.31,0.27 \mathrm{Kg} / \mathrm{kW}$-hr. The minimum BSFC $0.27 \mathrm{Kg} / \mathrm{kW}$-hr obtained at 240 bar IOP with $\mathrm{B} 20+15 \mathrm{lpm}$ of hydrogen. This is due to the higher most heat liberate during the premixed combustion [13]. BSFC decreases with increasing IOP because of the improved combustion and supply of additional energy.

\section{C.Combustion Parameter}

From the figures 6,7 and 8 demonstrates the variation of cylinder pressure vs. crank angle at different IOP and various test fuels at 100\% load condition. The cylinder pressure at 200 bar for test fuels of pure diesel, B20, $\mathrm{B} 20+51 \mathrm{pm}, \mathrm{B} 20+10 \mathrm{lpm}$, and B20+151pm are 50.57, 50.83, 54.49, 54.55, and 55.03, while at the IOP of 240 bar were 50.95, 51.95, 53.29, 54.15 and 54.42. The raise in Cylinder Peak pressure from 200 to 240 bar injection operating pressure may be attributed to the smaller delay period due to increase in cylinder temperature preceded by appropriate atomization [14] and premixed combustion. In a dual fuel engine the tendency of raise in peak pressure is due to more energy release rate.

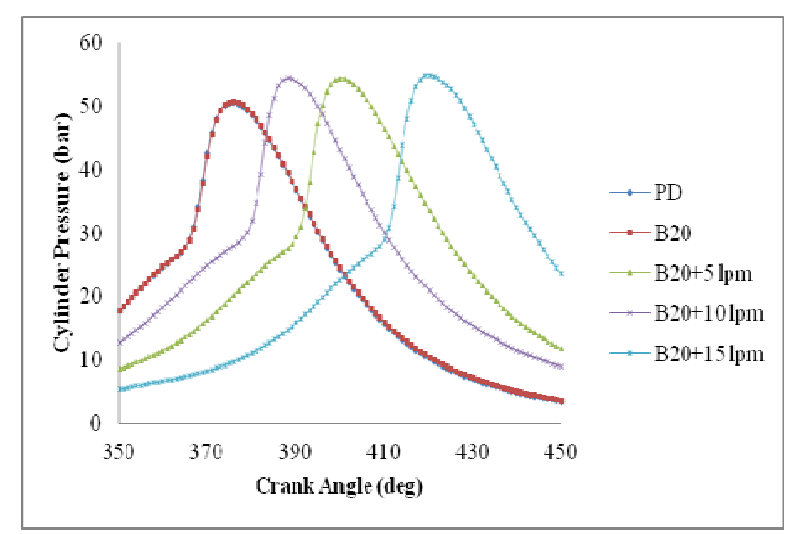

Fig 6 Comparison of Cylinder pressure vs. Crank Angle at 200 bar

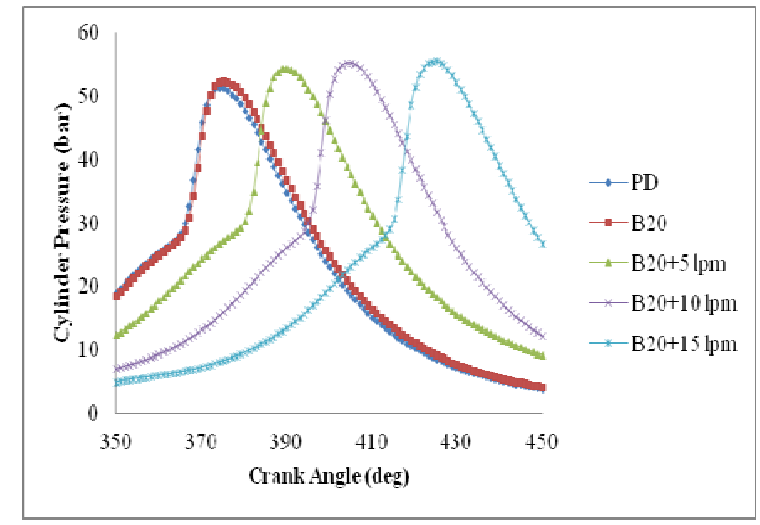

Fig 7 Comparison of Cylinder Pressure vs. Crank Angle at 220 bar 


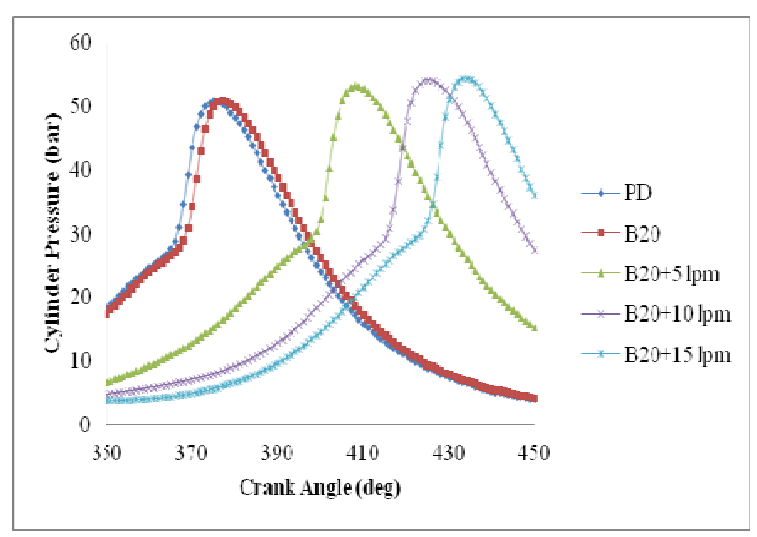

Fig. 8 Comparison of Cylinder Pressure vs.Crank Angle at 240 bar

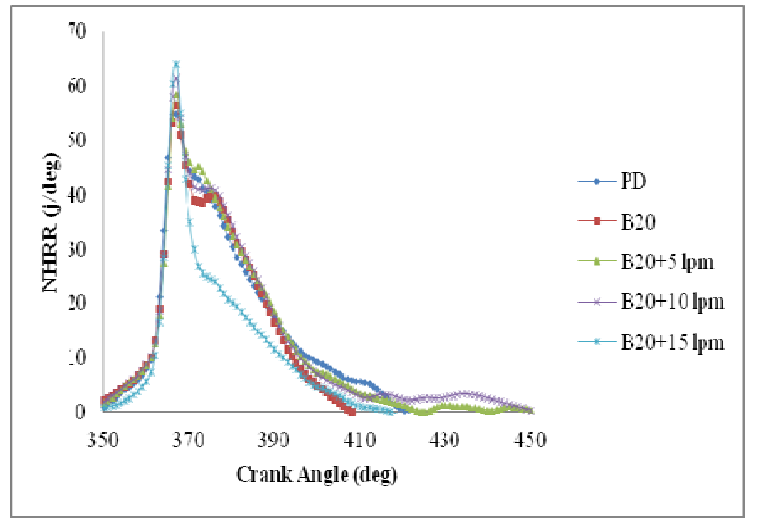

Fig 9 Comparison of NHHR vs. Crank Angle at 200 bar

From the figures 9, 10 and 11 demonstrates the variation of Net Heat Release Rate vs. crank angle at different IOP and various test fuels at 100\% load condition. The NHRR at 200 bar for test fuels of pure diesel, B20, $\mathrm{B} 20+5 \mathrm{lpm}, \mathrm{B} 20+10 \mathrm{lpm}$, and B20+15lpm are 56.58, 56.66, 58.31, 60.17, and 62.73, while at the IOP of 240 bar were 58.31, 60.17, 61.72, 63.39 and 68.37. NHRR increases from 200 to 240 bar injection opening pressure, because of more increase of pilot fuel in the combustion chamber, the combustion period is shortened [15], the incylinder peak pressure raises subsequently the peak value of heat release rate also increases [16].

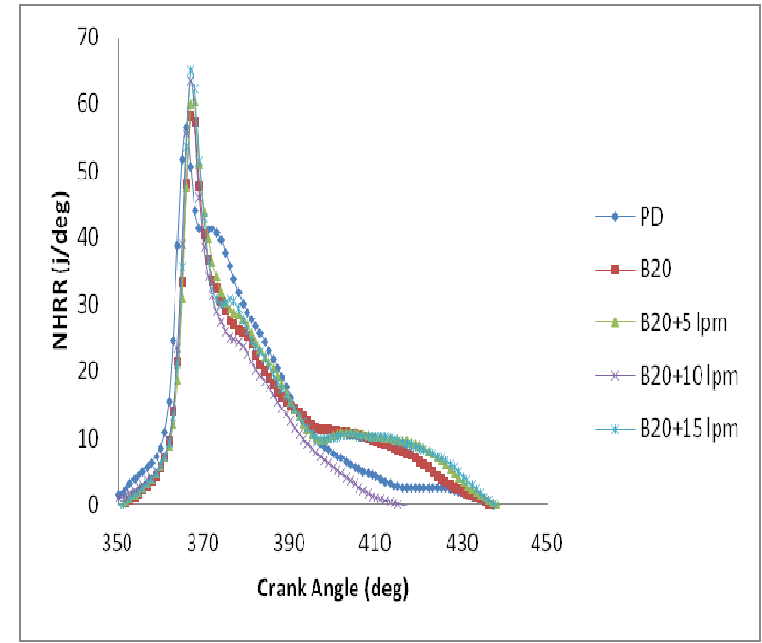

Fig. 10 Comparison of NHHR vs. Crank Angle at 220 bar

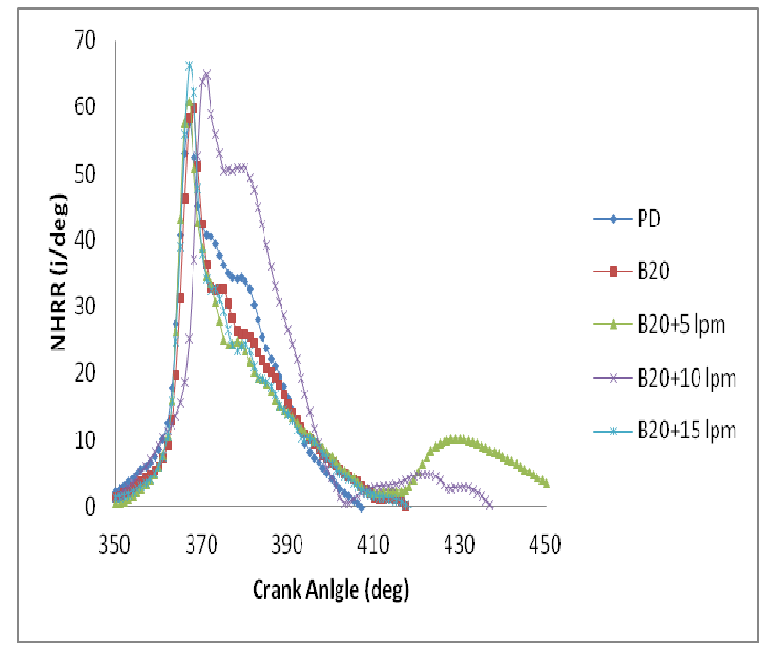

Fig.11 Comparison of NHHR vs. Crank Angle at 240 bar

\section{Emission Parameter}

The disparity of CO emission with the IOP is described in Fig. 12. CO emissions at 100\% load for IOP of 200 bar is $0.29, .27,0.22,0.17$, and 0.15 for the test fuels of pure diesel, B20, and B20 with hydrogen at 5, 10, and $15 \mathrm{lpm}$ of flow rate. The CO emission for the KOME operation is considerably lower than that of diesel and dual fuel operation because of the presence of oxygen in KOME, gives a complete oxidation of $\mathrm{CO}$, hence $\mathrm{CO}$ reduces. The hydrogen energy share increases with significantly reducing the $\mathrm{CO}$ emissions. The supplement of hydrogen significantly improves the many ignition centers in the combustion chamber and gives a lower $\mathrm{CO}$ emission. The CO emissions at $100 \%$ load for IOP of 220 , and 240 bar is $0.28,0.27,0.16,0.11$ and $0.048 \%$ vol and $0.25,0.23,0.06,0.02$ and $0.004 \%$ vol respectively. CO emissions reduce from IOP of 200 to 240 bar, because of complete combustion of the minor droplets [17]. 


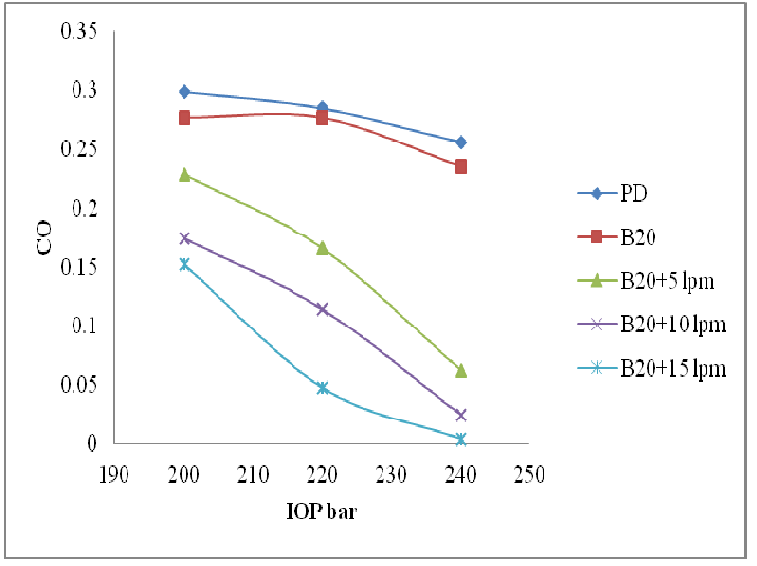

Fig.12 Comparison of $\mathrm{CO}$ emission vs. IOP

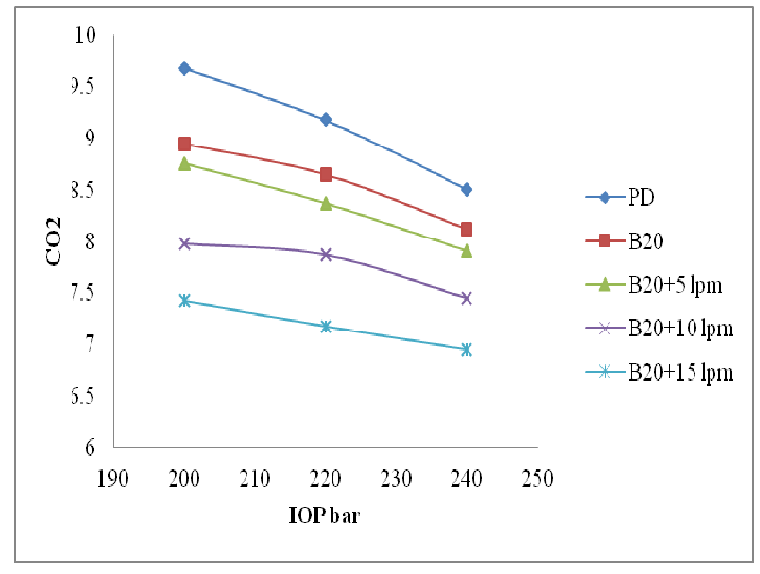

Fig.13 Comparison of Carbon dioxide vs. IOP

The difference of $\mathrm{CO}_{2}$ emission with the IOP is illustrated in Fig. 13. $\mathrm{CO}_{2}$ emissions at $100 \%$ load for IOP of 200 bar is $9.68,8.95,8.75,7.98$, and $7.43 \%$ vol for the test fuels of pure diesel, B20, and B20 with hydrogen at 5,10 , and $15 \mathrm{lpm}$ of flow rate. Bio diesel is oxygenated fuel, which burns clearly to produces less $\mathrm{CO}_{2}$ emission. While the addition of hydrogen to the blend $\mathrm{B} 20$ which shows decrease of $\mathrm{CO} 2$ emission, the reason behind this is due to complete combustion [18]. The $\mathrm{CO}_{2}$ emissions at $100 \%$ load for IOP of 220, and 240 bar is $9.18,8.65,8.37,7.87$, and $7.18 \%$ vol. and $8.51,8.12,7.91,7.45$ and $6.95 \%$ vol respectively. $\mathrm{CO}_{2}$ emissions reduce from IOP of 200 to 240 bar due to the better mixing and proper utilization of air. This resulted as complete combustion.

The variation of NOx emission with the IOP is illustrated in Fig. 14. NOx emissions at 100\% load for IOP of 200 bar is 829, 9501027,1134 , and 1245 ppm for the test fuels of pure diesel, B20, and B20 with hydrogen at 5, 10 , and $15 \mathrm{lpm}$ of flow rate. The NOx emission increase with increasing IOP is due to the higher oxygen concentration in B20. While the induction of hydrogen to B20 increases the cylinder temperature due to drop in volumetric efficiency. The NOx emissions at 100\% load for IOP of 220, and 240 bar is 841, 964, 1032,1149 and $1262 \mathrm{ppm}$ and 886, 998, 1069, 1189, and $1326 \mathrm{ppm}$ respectively. Concentration of NOx increases from IOP of 200 to 250 bar, because of fast combustion and more in-cylinder gas temperature, peak pressure reached with elevated pilot injection pressure.

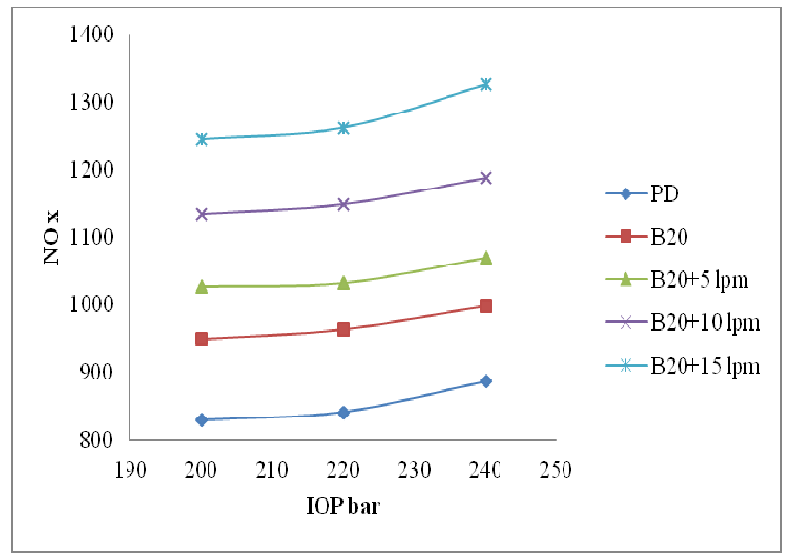

Fig.14 Comparison of NOx Emission vs. IOP

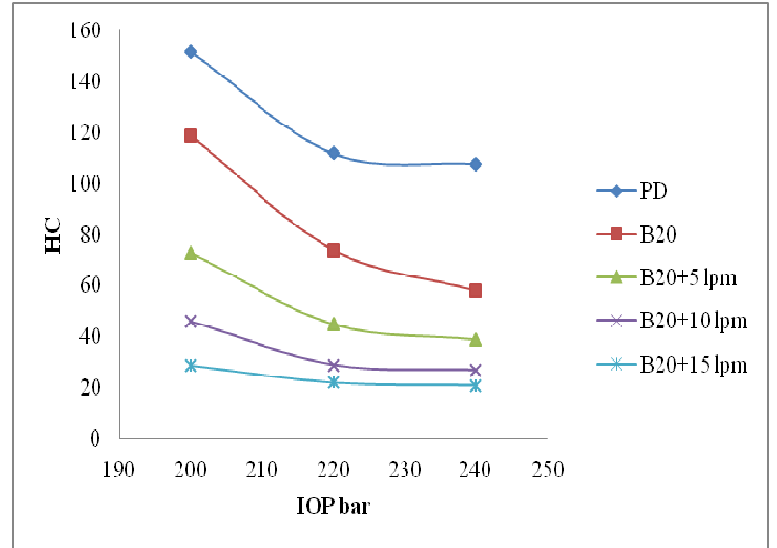

Fig.15 Comparison of HC Emission vs IOP

The variation of HC emission with the IOP is illustrated in Fig. 15. HC emissions at 100\% load for IOP of 200 bar is 152, 119, 73, 46, and $29 \%$ vol for the test fuels of pure diesel, B20, and B20 with hydrogen at 5, 10, and $15 \mathrm{lpm}$ of flow rate. The higher cetane number and atomization of B20 results decrease in HC emission due to shorter ignition delay. While adding hydrogen with different proportions cause faster rate of combustion. The $\mathrm{HC}$ emissions at $100 \%$ load for IOP of 220 , and 240 bar is $112,74,45,29$, and $22 \%$ and $108,58,39,27$, and $21 \%$ vol respectively. HC moderated from IOP of 200 to 240 bar, because of accurate combustion and high cylinder wall temperatures reduces in quench layer. 


\section{IV.CONCLUSION}

A single cylinder compression ignition diesel engine was operated successfully using B20 as pilot fuel and hydrogen as introduced fuel at unlike injection operating pressures. Tests carried out at 200, 220, and 240 bar IOP point out that 240 bar IOP is most favorable pressure for improved performance, combustion and smallest amount emissions. The following conclusions are recapitulated based on the experimental results acquired for hydrogen operated engine with B20 as pilot fuel injected with 240 bar injection operating pressure and contrasted to pure diesel operation at base line injection opening pressure of $200 \mathrm{bar}$ at $100 \%$ load.

- B20 and B20 with hydrogen can be directly used in diesel engines with or without any modifications.

- The maximum BTE of $27 \%$ was observed at IOP of about 240 bars and at $100 \%$ engine load. BTE was found lowest at 200 bars.

- B20 with $151 \mathrm{pm}$ of hydrogen reduces BSFC by $27 \%$. Brake specific fuel consumption was continuously decreasing with the increase in IOP. Minimum brake specific fuel consumption was noticed at 240 bars and BSFC was found maximum at 200 bar of injection operating pressure.

- Peak cylinder pressure and Net heat release rate was detected at 240 bar of IOP.

- Compared with pure diesel, exhaust emissions of $\mathrm{CO}, \mathrm{CO} 2$ and $\mathrm{HC}$ are reduced while NOx emissions are increased with B20 and B20 among hydrogen with diesel.

Experimental analysis exposed that the supply of $15 \mathrm{lpm}$ hydrogen in direct injection diesel engine running on B20 and operated with increased injection operating pressure of 240 bar gives maximum brake thermal efficiency than at 200 bar. Also, $\mathrm{HC}$ and $\mathrm{CO}$ emissions are reduced at the penalty of increased NOx emissions than that of diesel fuel operation

\section{ACKNOWLEDGMENT}

The author would like gratefulness to Dr. Sudheer Prem Kumar Bellam and Dr. Vijaya Kumar Reddy K, Professor in MED, JNTUH CEH, for proving their valuable supervision and great hold up to carrying this work. The author would like to wish Lords Engineering College Hyderabad for giving permission to conduct this experimental work.

\section{REFERENCES}

[1] Vanegas, A., Won, H., Felsch, C., Gauding, M., and Peters, N., "Experimental Investigation of the Effect of Multiple Injections on Pollutant Formation in a Common-Rail DI Diesel Engine”, SAE Paper 2008-01-1191, 2008.

[2] Shuofeng Wang, Changwei Ji and Bo Zhang, "Starting a spark-ignited engine with the gasoline- hydrogen Mixture," International Journal of hydrogen energy , 36(2011)4461-4468.

[3] Culshaw FA. The potential of Biodiesel from oilseed rape. ProcInst Mech Eng 1993;207:173-7.

[4] Hunke AL, BarsicNJ. Performance and emission characteristics of a naturally aspirated diesel engine with vegetable oils (Part-2). SAE Paper No 810955, 1981.

[5] Gopalakrishnan KV, Rao PS. Use of non-edible vegetable oils as alternate fuels in diesel engines. DNES Project Report, I.C.E.lab, IIT Madras-36, 1996.

[6] R.S.Kureel, C.B.Sing, A.K.Gupta, and Ashutosh Pandey. KARANJA A potential source of bio- diesel.National Oilseeds \& Vegetable oils Development board ( Ministry of Agriculter, Govt. Of India) 86, Sector-18,Institutional Area, Gurgaon 122015, May 2008.

[7] Pravesh Chandra Shukla, Tarun Gupta, Nitin Kumar Labhsetwar, Avinash Kumar Agarwal. Physico-chemical speciation of particulates emanating from Karanja biodiesel fuelled automotive engine. http://dx.doi.org/10.1016/j.fuel.2015.07.076, 0016-2361/@ 2015 Elsevier Ltd. All rights reserved.

[8] Ahmed Syed, Syed Azam Pasha Quadri, G Amba Prasad Rao, and Mohd Wajid. Experimental investigations on DI (Direct injection) diesel engine operated on dual fuel mode with hydrogen and Mahua oil methyl ester (MOME) as injected fuels and effects of injection opening pressure. http://dx.doi.org/10.1016/j.applthermaleng.2016.11.152

[9] M. Senthil Kumar, A. Ramesh, B. Nagalingam. Use of hydrogen to enhance the performance of a vegetable oil fuelled compression ignition engine. 0360-3199/03/\$ 30.00 ? 2003 International Association for Hydrogen Energy. Published by Elsevier Science Ltd. All rights reserved. PII: S0360-3199(02)00234-3

[10] Rachan D Shekar, and H R Purushothama. Hydrogen Induction to Diesel Engine Working on Biodiesel:AReview.(http://creativecommons.org/licenses/by-nc-nd/4.0/).doi: 10.1016/j.proeps.2015.06.037.

[11] Hohenberg GF. Advanced approaches for heat transfer calculations. SAE Paper No 790825, 1979.

[12] Bauer C and Forest T. Effect of Hydrogen Addition on the Performance of Methane-Fueled Vehicles. Part I: Effect on S.I. Engine performance. Int J Hydrogen Energy (26) (2001) 55-70

[13] Bari S. Effect of carbon dioxide on the performance of biogas/diesel dual-fuel engine. Renew Energy 1996;9:1007-10.

[14] Arai M, Tabata M, Hiroyasu H, Shimizu M. Disintegration process and spray characterization of fuel jet injected by a diesel nozzle. SAE paper 1984840275.

[15] Liu J, Yao A, Yao C. Effects of diesel injection pressure on the performance and emissions of a HD common-rail diesel engine fueled with diesel/methanol dual fuel. Fuel 2015; 140:192-200.

[16] Jaichandar S, Annamalai K. Combined impact of injection pressure and combustion chamber geometry on the performance of a biodiesel fueled diesel engine. Energy 2013; 55:330-339.

[17] Park W, Lee CS. Macroscopic and microscopic characteristics of a fuel spray impinged on the wall. Exp Fluid 2004;37:745-62.

[18] Jacob Wall. Effect of Hydrogen Enriched Hydrocarbon Combustion on Emissions and Performance. Department of Biological and Agricultural Engineering University of Idaho.SAE 